\title{
Methaemoglobinaemia after cardiac catheterisation: a rare cause of cyanosis
}

\section{Kaendler, A Dorszewski, I Daehnert}

Heart 2004;90:e51 (http://www.heartjnl.com/cgi/content/full/90/9/e51). doi: 10.1136/hrt.2004.038554

Two young women had unexpected cyanosis a few hours after cardiac catheterisation for electrophysiological investigation. The first patient had atrioventricular septal defect, had undergone repeated surgical interventions, and was referred because of atrial flutter. The second patient had ablation of an accessory pathway in Wolff-Parkinson-White syndrome. Local anaesthesia was performed with $40 \mathrm{ml}$ prilocaine $2 \%$. Cyanosis with oxygen saturation of $85 \%$ developed in both patients a few hours after the electrophysiological investigation. The patients were transferred to the intensive care unit and for the first patient a considerable diagnostic effort was made to rule out morphological complication. Finally methaemoglobinaemia of $16.7 \%$ and $33.4 \%$, respectively, was found. Cyanosis resolved within 24 hours and did not reappear. Underlying glucose-6-phosphate dehydrogenase deficiency and erythrocyte-methaemoglobin reductase deficiency were ruled out. Physicians should be aware of this rare side effect of local anaesthetics in patients with unexpected cyanosis.

\footnotetext{
C
} yanosis caused by methaemoglobinaemia is a rare condition beyond infancy. Methaemoglobin is the oxidised form of haemoglobin, and cannot bind and transport oxygen. Normal concentration accounts for less than $1 \%$ of circulating haemoglobin. The concentration is increased in heterozygous carriers of variants of the $M$ chain of the haemoglobin molecule, who are cyanotic life long. Homozygous carriers have a dramatically reduced life expectancy. ${ }^{12}$ Under normal conditions methaemoglobin is reduced in the erythrocytes to haemoglobin by methaemoglobin reductase. ${ }^{3}$ The NAD phosphate enzyme system (NADPH3), which needs glucose-6-phosphate dehydrogenase (G6PD) as a cofactor, is an important alternative pathway. ${ }^{3}$ So G6PD deficiency and methaemoglobin reductase deficiency have to be ruled out in cases of methaemoglobinaemia. Nevertheless, methaemoglobinaemia can rarely occur in patients with normal enzyme activity and normal haemoglobin under the influence of oxidants such as topical anaesthetics, sulfonamides, and nitrates.

\section{CASE REPORT}

\section{Case 1}

A 31 year old woman with atrioventricular septal defect had undergone repeated surgical interventions, among them mitral valve replacement after infective endocarditis. She was referred for electrophysiological investigation because of atrial flutter. Local anaesthesia of both groins was performed with $800 \mathrm{mg}$ of prilocaine $(13.5 \mathrm{mg} / \mathrm{kg})$. Striking cyanosis with oxygen saturation of $85 \%$ emerged after the investigation. The patient felt otherwise well. Nevertheless she was transferred to the intensive care unit and received $2 \mathrm{l} / \mathrm{min}$ of oxygen through a nasal tube. Treatment with heparin was started. Echocardiography and radiography were performed to exclude pulmonary embolism and disturbances of the mechanical valve. Finally, two and a half hours after local anaesthesia methaemoglobin was found to be $16.7 \%$, decreasing to $1.7 \%$ next morning. Methaemoglobin reductase activity and G6PD activity were normal.

\section{Case 2}

A 16 year old girl with Wolff-Parkinson-White syndrome had catheter ablation of the accessory bundle. Four punctures of both groins were performed to position the catheters. Local anaesthesia of both groins was performed with $40 \mathrm{ml}$ prilocaine $2 \%$ ( $800 \mathrm{mg}$ equivalent to $18 \mathrm{mg} / \mathrm{kg}$ ). Notable cyanosis with oxygen saturation of $85 \%$ appeared three hours after the beginning of the investigation. Apart from vomiting she remained free of symptoms with $2 \mathrm{l} / \mathrm{min}$ of oxygen supply. Morphological complications were ruled out by echocardiography and radiography of the thorax. Methaemoglobin concentration was found to be $33.4 \%$ three hours after the beginning of the investigation and diminished slowly to $3.7 \%$ by the next morning. Methaemoglobin reductase and G6PD were normal.

\section{DISCUSSION}

Methaemoglobinaemia is a rare complication in the use of local anaesthetics. It was seen in epidural infusion of lidocaine, after local anaesthesia with benzocaine for gastrointestinal endoscopy, after anaesthesia with prilocaine for removal of teeth, and after local anaesthesia for transoesophageal echocardiography. ${ }^{4-7}$ Until now methaemoglobinaemia after cardiac catheterisation has not been reported. An early study on dose response by Nolte and colleagues ${ }^{8}$ showed a great interindividual variation in methaemoglobin formation after subcutaneous and intramuscular injection of prilocaine. Prilocaine was much more rapidly absorbed by the synovium than by subcutaneous tissue for arthroscopy. ${ }^{9}$ Scott and colleagues ${ }^{10}$ observed methaemoglobinaemia in every patient given more than $900 \mathrm{mg}$ of prilocaine for intercostal or epidural blockade. If necessary, methaemoglobinaemia can be treated with $1 \mathrm{mg} / \mathrm{kg}$ methylene blue intravenously, which was not necessary in our patients.

The recommended maximum dose of prilocaine is $8 \mathrm{mg} /$ $\mathrm{kg}^{2}{ }^{2}$ so both of our patients were accidentally overdosed ( $13.5 \mathrm{mg} / \mathrm{kg}$ and $18 \mathrm{mg} / \mathrm{kg}$, respectively).

Keeping in mind the great interindividual differences in methaemoglobin response reported by Nolte and colleagues, ${ }^{8}$ one should be aware of this side effect even among patients treated with no more than the recommended doses of local anaesthetics. This awareness may help to recognise methaemoglobinaemia promptly and avoid unnecessary diagnostic procedures. 


\section{Authors' affiliations}

L Kaendler, A Dorszewski, I Daehnert, Heart Centre, University of Leipzig, Leipzig, Germany

Correspondence to: Dr Ingo Daehnert, Klinik fuer Kinderkardiologie, Herzzentrum, Universitaet Leipzig, Struempellstrasse 39, 04289 Leipzig Germany; ingodaehnerł@yahoo.de

Accepted 28 April 2004

\section{REFERENCES}

1 Clemens MR. Blut. In: Siegenthaler W, ed. Klinische Pathophysiologie. Stuttgart: Thieme, 2001:447-86.

2 Coleman MD, Coleman NA. Drug-induced methaemoglobinaemia: treatment issues. Drug Saf 1996; 14:394-405.
3 Wilburn-Goo D, Lloyd LM. When patients become cyanotic: acquired methemoglobinemia. J Am Dent Assoc 1999;130:826-31.

4 Conroy JM, Baker JD, Martin WJ, et al. Acquired methemoglobinemia from multiple oxidants. South Med J 1993:86:1156-9.

5 Saleem MA, McClung JA, Peterson SJ. Hypoxemia sans hypoxemia. Heart Dis 2000;2:116-7.

6 Kreutz RW, Kinni ME. Life-threatening toxic methemoglobinemia induced by prilocaine. Oral Surg Oral Med Oral Pathol 1983;56:480-2.

7 Fisher MA, Henry D, Gillam L, et al. Toxic methemoglobinemia: a rare but serious complication of transesophageal echocardiography. Can J Cardiol 1998; 14:1157-60.

8 Nolte H, Dudeck J, Hultzsch B. [Studies of the dose dependency of methemoglobin development after administration of prilocaine (Citanest)]. Anaesthesist 1968;17:343-6.

9 Debruyne D, Moulin M, Thomassin C, et al. Prilocaine in arthroscopy: clinical pharmacokinetics and rational use. Clin Pharmacol Ther 1985;38:549-53.

10 Scott DB, Owen JA, Richmond J. Methaemoglobinaemia due to prilocaine. Lancet 1964;171:728-9. 